\title{
INDEPENDENT RESEARCH AND DEVELOPMENT EXPENDITURES: A STUDY OF THE GOVERNMENT CONTRACT AS AN INSTRUMENT OF PUBLIC POLICY
}

\author{
Richard N. FLINT*
}

Today, more than ever before, the federal government is in the business of research and development work. Official estimates place the total funds obligated in the research and development ( $R \& D)$ programs undertaken by the various agencies of the federal government during fiscal year Ig63 at almost $\$ \mathrm{r} 4.7$ billion, ${ }^{1}$ and our newspapers are filled with articles concerning the size and diversity of these programs. ${ }^{2}$ However, almost all the comment regarding $R \& D$ is addressed to the direct support of research by the federal government, either through intramural research undertaken directly by government employees at federal installations, or through direct support of research by means of government contracts and grants for $R \& D$. Scant attention has been given to the indirect support of research and development through partial reimbursement of a contractor's independent research and development (IR\&D) program. By definition IR\&D is a contractor's research and development which is not sponsored by a government contract or grant, ${ }^{3}$ but IR\&D may be supported indirectly as an overhead item if the contractor has cost-reimbursement type contracts with the federal government. An example will serve to illustrate.

Charley Brown Electronics, Inc., as its name implies, is engaged in research, development, and manufacture of various exotic electronic components which are utilized by industry and government. In 1963 Brown's commercial sales were $\$ 35$ million, and its sales on a fixed-price basis to the federal government were $\$ 28$ million. Brown is also operating under various cost-reimbursement type contracts in which it incurred direct labor and material costs of $\$ 40$ million during 1963. In computing the overhead attributable to these cost-reimbursement contracts, it is learned that the total overhead costs, excluding IR\&D, were $\$ 30$ million. In addition, Brown has undertaken on its own initiative, a substantial IR\&D program, con-

* B.A. 1957, University of Minnesota; J.D. I960, Northwestern University. Member of the bars of Minnesota, Illinois, and U.S. Supreme Court. Presently associated with the firm of Cant, Haverstock, Beardslcy, Gray, \& Plant, Minneapolis, Minn.

The views expressed are the author's own and do not purport to reflect those of the Defense Department or any other government agency.

${ }^{1}$ U.S. National Science Foundation, Federal Funds for Science XI, at 2 (1963).

${ }^{3}$ See, e.g., N.Y. Times, Sept. 22, I963, $\$ 3$.

"Armed Services Procurement Regulation (ASPR) I5-205.35(c). Unless otherwise indicated, all references are to the current ASPR (January 1963 edition, including Revision No. 3, dated Nov. I5, I963). It is printed in subchapter A of chapter I, title 32 , Code of Federal Regulations. 
sisting of a variety of projects relating to advanced means of communication and the improvement of several existing communication systems. The total costs of this IR\&D program in 1963 were $\$ 20$ million. Assuming that the total direct labor and material costs of the commercial sales and the government fixed-price sales were $\$ 40$ million, the overhead and IR\&D (if allowable) will be apportioned fifty per cent to the government cost contracts. Accordingly, the total cost of the cost contracts to the government will be $\$ 65$ million ( $\$ 40$ million in direct expenditures plus $\$ 10$ million in IR\&D and \$I5 million in other overhead). In other words, the government has paid for half of the IR\&D.

At its best, reimbursement of IR\&D means that the government initiates and encourages research and development in innumerable areas and advances science generally by paying only a fraction of the cost. At its worst, reimbursement of IR\&D means that the government has expended public funds on a program of purely commercial interest to a particular contractor, a program which would have been undertaken even without the expenditure of public funds, and a program which is being duplicated elsewhere by another company working without government support. Moreover, there is no assurance that the results of the IR\&D, even though supported in part by public funds, will be made available to the scientific community generally.

This paper will explore in detail the various policies which have governed the reimbursement of IR\&D from time to time, and will point up certain of the problem areas. Current efforts to develop government-wide IR\&D proposals will be evaluated, and a few suggestions will be made for the improvement of existing policies and procedures in order to protect the individual government contractor, as well as the public at large. The discussion will center upon the Defense Department, since this agency is by far the largest government buyer and it continues to have the largest R\&D budget. ${ }^{4}$ A recent estimate within the Defense Department places the total cost of IR\&D to that agency during rg62 alone at $\$ 900$ million.

IR\&D EXPENDITURES TO T960

\section{A. Predetermined Overhead Rates}

The Armed Services Procurement Regulation (ASPR) provisions dealing with the allowability of IR\&D have become increasingly sophisticated with time. The r948 edition of ASPR provided at 15-204(s) that research and development costs were allowable so long as "specifically applicable to the supplies or services covered by the contract," but section 15-205(j) provided that "general research" was unallow-

\footnotetext{
"The total obligations incurred for research and development and R\&D plant by the Defense Department during fiscal year 1963 were estimated at $\$ 7.8$ billion, U.S. National Science Foundatzon, FrdERAL Funds fOR SCIENCE XI, at 2 ( 1963 ).

The applicable text of the section is as follows:

"15-204 Examples of Items of Allowable Costs. Subject to the requirements of paragraph 15-20r with
} 
able "unless specifically provided for elsewhere in the contract." Since general research, by definition, would almost never be "specifically applicable" to the supplies or services being purchased under a particular contract, a specific provision elsewhere in the contract was necessary to authorize reimbursement. Although applied research and development might be in a field in which the government had a definite interest, such costs were not reimbursable unless they were shown to be specifically applicable to the particular contract under which reimbursement was sought.

Prior to 1956 , however, retroactive reimbursement of research and development costs was not as serious a problem as it is today. This is because the indirect costs of a government cost-plus-fixed-fee (CPFF) contractor were reimbursed through negotiated, predetermined overhead rates which were incorporated into the contract before the costs were incurred. Thus, the matter of general research costs was taken up before the costs were incurred, and the agreement between the parties was incorporated in the contract, thereby qualifying under 15-205(j)'s requirement that such costs must be "specifically provided for elsewhere in the contract." This procedure also assured that the contracting officer would have a voice in the research undertaken by the contractor if the contractor was to be reimbursed therefor.

However, on January 27, 1956 , the Comptroller General ruled that the use of predetermined overhead rates violated the congressional prohibition against contracts providing for payment on the basis of cost-plus-a-percentage-of-cost (CPPC). ${ }^{7}$ In so holding, the Comptroller General noted that the evils of this system of costreimbursement had been repeatedly discussed-the contractor was encouraged to increase his profit by carelessly or deliberately increasing his cost at the expense of the government. ${ }^{8}$

\section{B. Postdetermined Overhead Rates}

The 1955 edition of ASPR did not change the underlying provisions relative to "research and development" and to "general research"; ASPR I5-204(s) and I5-205(j) continued the same language used in the r948 ASPR. ' However, these provisions

respect to the general basis for determining allowability of costs, and irrespective of whether the particular costs are treated by the contractor as direct or indirect, the following items of costs are considered allowable within the limitations indicated:

…

(s) Research and development specifically applicable to the supplies or services covered by the contract." The text of the section is as follows:

"I5-205 Examples of Items of Unallowable Costs. Irrespective of whether the particular costs are treated by the contractor as direct or indirect, the following items of cost are considered unallowable, except as indicated:

(j) General research, unless specifically provided for elsewhere in the contract."

${ }^{7}$ B-I 26794 , Jan. 27, x956, 35 Decs. Comp. Gen. 434 (1956).

8 "The evils attributed to this system of contracting have been elaborated on many times. They consist, essentially, in abetting the temptation and possibility that a contractor may increase his profit by carelessly or deliberately increasing his cost at the expense of the Government under a reimbursable contract." 35 Decs. Comp. GeN. 434, at 435 .

${ }^{\circ}$ See notes 5 and 6 , stupra. 
were applied in an entirely different atmosphere due to the advent of the revised method of negotiating overhead rates which was necessitated by the Comptroller General opinion cited above.

The revised method makes use of postdetermined overhead rates, i.e., rates determined after the close of the contract period. ${ }^{10}$ A provisional overhead rate is established prior to the contract period for interim billing purposes only, ${ }^{11}$ this tentative rate being based upon the contractor's previous cost experience under the same or similar contracts. Upon the expiration of the period specified in the contract schedule, the contractor submits a proposed final overhead rate which reflects the overhead costs actually incurred during the period. The contractor's proposal is submitted to the cognizant audit agency for advisory audit, and it is subjected to the standards of ASPR section fifteen, part two, which have been incorporated into the contract. ${ }^{12}$ Ultimately, a negotiated final overhead rate is agreed to by the parties, and this rate is incorporated into the contract. The term "rate" is used even though the parties are actually dealing with the allowability of particular items as overhead and then with an apportionment of the overhead, because the parties ultimately express the allowable overhead as a specific percentage of the direct cost base. Thus the form of the old predetermined overhead rate is preserved while the result is quite different.

The result is different first because the postdetermined overhead rate, not being part of the original contract, does not qualify as a specific provision elsewhere in the contract, as was required under the pre-rg6o ASPR to justify the inclusion of general research costs in overhead. Secondly, the contracting officer's authority to bind the government is much more limited at the time he negotiates the postdetermined overhead rate than it was when he negotiated the original contract. If at the time of negotiating the original contract, the contracting officer agreed to reimburse general research costs in whole or in part, this would constitute part of the legal consideration for the contractor's performance. When general research

${ }^{10}$ For a more complete discussion of the negotiated overhead rates procedure, see ASPR sec. III, Part 7. See also, Paul M. Trueger, Accounttng Guide for Defense Contracts cc. 17-ig (4th ed. 1963).

${ }^{11}$ ASPR 3-70r.2.

12 The Negotiated Overhead Rates clause (Dec. 1956) provided in part as follows: . .

"(b) The Contractor, as soon as possible but not later than ninety (90) days after the expiration of each period specified in the Schedule, shall submit to the Contracting Officer . . . a proposed final overhead rate or rates for that period based on the Contractor's actual cost experience during that period, together with supporting cost data. Negotiation of final overhead rates by the Contractor and the Contracting Officer shall be undertaken as promptly as practicable after receipt of the Contractor's proposal.

"(c) Allowability of costs and acceptability of cost allocation methods shall be determined in accordance with ASPR, Section XV, Part 2, as in effect on the date of this contract.

"(d) The results of each negotiation shall be set forth in an amendment to this contract, which shall specify (i) the agreed final rates, (ii) the bases to which the rates apply, (iii) the periods for which the rates apply, and (iv) the specific items treated as direct costs or any changes in the items previously agreed to be direct costs.

....

"(f) Any failure by the parties to agree on any final rate or rates under this clause shall be considered a dispute concerning a question of fact for decision by the Contracting Officer within the meaning of the clause of this contract entitled 'Disputes." 
costs are first discussed as part of the final overhead rate negotiations, the contracting officer's authority is merely to apply the provisions of ASPR, section fifteen, part two, which have been incorporated into the contract. ${ }^{13}$ If there was no provision for reimbursement of general research in the original contract, an agreement to reimburse such costs negotiated after the contract period would appear to be an amendment without consideration. Such an amendment without consideration would be beyond the authority of the contracting officer and therefore not binding on the government. ${ }^{14}$

\section{Recovery of IR\&D Expenditures Under Public Law 85-804}

When the revised method of negotiating overhead rates was adopted by the Department of Defense in 1956, the Negotiated Overhead Rates clause (December 1956) was incorporated into all new contracts without full consideration of the effect which this would have upon the reimbursement of general research expenses. Thus, a number of contractors who had previously been reimbursed general research expenses under a predetermined overhead rate continued their independent research programs apparently upon the supposition that government reimbursement would be continued. Upon the expiration of the contract period, the government refused to reimburse the general research costs because reimbursement was not "specifically provided for elsewhere in the contract," and the contractors sought relief under the provisions of Public Law $85-804{ }^{15}$

The contractor has prevailed in a number of these cases before the Army Contract Adjustment Board, the Navy Contract Adjustment Board, and the Air Force Contract Adjustment Board. In the only one of these cases which has been made available to the public in printed form, Westinghouse Electric Corp. ${ }^{16}$ the Army Contract Adjustment Board amended the contract terms retroactively in order to correct a mutual mistake. ${ }^{17}$ In so doing the Board stated the issue as being whether the terms of the original contract "express the true intent of Westinghouse and the United States" as to the allowability of general research. Although the matter had not been discussed at the time the contracts were executed nor at the time the Negotiated Overhead Rates clause was inçorporated therein, the Board found that the intent of the parties had been to continue inclusion of general research in overhead. The Board emphasized the long history of allowing general research to Westinghouse as part of the predetermined overhead rate, and it concluded that had there been any.intent to change this longstanding practice, this would have been discussed by, the parties. In another recent case, however, recovery has been

${ }^{13}$ See paragraph (c) of the Negotiated Overhead Rates clause, note 12 supra.

${ }^{14}$ Ms. Comp. Gen. B-r 50994 , April 3, 1963. See also B-125769, Oct. 24, 1955, 35 Decs. Comp. Gen. 230, at 232 (1955); Steel Improvement \& Forge Co:, ASBCA No.'7143, I962 BCA I3587, at I8, 136 .

${ }_{15} 72$ Stat. 972 , 50 U.S.C. $\$ \$ 1431-35$ (1958). See also ASPR $\$$ I7.

10 ACAB No. roio, Feb. 14, 196r, reprinted in George Washington University, Correction of Mistakes in Contracts iI (Gov't Cont. Monograph-No. I, Ig6r).

${ }^{17}$ See ASPR I7-204.3(i). 
denied where the contractor failed to prove that the government intended to reimburse the general research program prior to the costs being incurred. ${ }^{18}$

Thus it would appear that in those cases meeting the rather rigorous requirements of Public Law 85-804, the contract adjustment boards will authorize retroactive amendment of existing contracts to allow reimbursement of general research. It should be emphasized, however, that the contractor has the burden of proving not only his own intent, but also the government's intent, prior to the costs being incurred, that such costs be reimbursed. This contractor burden of proof is particularly difficult where the government has not knowingly reimbursed general research costs over a considerable period of time prior to the year in question.

\section{Must An Independent Research Program Be Burdened With Its Proportionate Share of Overhead and Other Indirect Costs}

An additional problem arose in those cases where general research was conceded to be an unallowable item of overhead-that is, where the contract failed to "specifically provide" for its reimbursement. Admittedly in these situations the direct cost of labor and materials expended on the general research program must be excluded from the reimbursable overhead. But must the direct research cost also be required to bear a proportionate part of the overhead expenses? ? $^{\mathbf{1 0}}$ An example will serve to highlight this issue.

Suppose that Corporation $A$ is engaged in research and development exclusively financed under CPFF government contracts. In addition, the contractor has an IR $\& D$ program relating to a totally new concept in home ice cream freezers which it hopes to develop commercially at some future time. The direct costs of this IR\&D program (i.e., the direct labor hours and materials) are excluded from contractor's overhead, since this IR\&D is not "specifically applicable" to the research services being supplied under the government contract and reimbursement is not "specifically provided for elsewhere in the contract."20 Suppose that the direct labor and material cost of the government contracts was $\$ 750,000$, while that of the IR\&D program was $\$ 250,000$. In addition, a research organization of this nature generates relatively high overhead costs, and Corporation $A$ had overhead costs of $\$ \mathrm{I}, 000,000$ in the fiscal year involved. If the IR\&D program is not burdened with its proportionate share of overhead, the cost of the government contracts will be $\$ I, 750,000$ while the IR\&D program will be charged only with its direct cost of $\$ 250,000$.

The IR\&D program presumably generated certain of the indirect costs such as electricity, payroll taxes, material handling costs, and the administrative costs of overseeing the program. It would be virtually impossible to segregate all the indirect costs thus occasioned; for example, the president of the company could

${ }^{18}$ Raytheon Co., Navy Contract Adjustment Board, Dec. 18, 1962, aff'd on rehearing, May $1, x^{\prime} 6_{3}$.

${ }^{10}$ The problem is discussed at this point because most of the cases arose under the pre-1960 ASPR, but the problem may also arise under the current ASPR in those instances where IR\&D is unallowable.

${ }^{20}$ See notes 5 and 6 supra. 
hardly be expected to maintain a record of the hours which he devoted to thinking about the IR\&D program. Thus, the most practical means of assuring that these IR $\& \mathrm{D}$-generated indirect costs be excluded from the overhead reimbursable under the government contract is to require that the direct IR\&D expenses bear a proportionate part of the overhead. In the example, therefore, the total cost of the government contracts would be $\$ 1,500,000$, and the IR\&D $\$ 500,000$.

In a very recent opinion, the Comptroller General has held that where IR\&D is nonallowable, the direct IR\&D costs must be burdened with their proportionate share of indirect expenditures, and both must be disallowed. ${ }^{21}$ Although the circumstances there presented arose under the pre-1960 ASPR, there is strong dicta in the opinion which indicates that the Comptroller General would reach the same result under the current ASPR. ${ }^{22}$ This opinion also is consistent with two previous Comptroller General opinions involving advertising expenses, ${ }^{23}$ the reimbursement of which has for many years been curtailed under the ASPR. ${ }^{24}$ In these previous opinions, the Comptroller General held that where a certain percentage of the direct cost of advertising was not reimbursable, the same proportion of the indirect costs-i.e., the administrative costs in operating the advertising department-must also be disallowed.

An early opinion of the ASBCA, International Industrial Development Co., Inc., ${ }^{25}$ reached the same result. In recent years, however, the ASBCA has reversed the reasoning of the International case without expressly mentioning that case. In Tracerlab, Inc., ${ }^{26}$ and two cases following it, ${ }^{27}$ the Board held that while certain general research costs incurred by the contractor were not specifically applicable to the work being done under the government contract and therefore were not reimbursable, this general research was not required to absorb its proportionate portion of contractor's overhead. These cases appear to give undue emphasis to the contractor's consistently-applied accounting practice. In a cost-reimbursement type contract, the contractor's acounting practice is always subject to the general test of reasonableness, allocability, and generally accepted accounting practices; ${ }^{28}$ and there are numerous cases in which the contractor has been required to deviate from his

${ }^{21}$ Ms. Comp. Gen. B-152462, Jan. 15, 1964.

23 "It is fundamental that the costs of any product or project include direct costs as well as indirect costs generated by that product or project, and there is nothing in part 2, section XV of ASPR, either prior or subsequent to revision No. 50, which would even suggest a departure from this basic principle." See also text accompanying note 32 infra.

${ }^{22}$ Ms. Comp. Gen. B-1 26I61 (Feb. I7 1956), Ms. Comp. Gen. B-I38650 (Oct. 2I, I959).

"See the current coverage in ASPR 15 -205.x.

20 ASBCA No. I72, June 30, 1950 .

20 ASBCA No. 4546, 1959-ז BCA \2221.

27 Technical Operations, Inc., ASBCA Nos. 5014 and 5031, 1959-2 BCA I 2455; National Research Corp., ASBCA No. 7524, I962 BCA I 3526, at 17,930:

"This board has had occasion to determine in several instances that the direct labor costs of general research are not properly included in the denominator base of this ratio [for apportioning overhead to the government contract] when the contractor's normal accounting practice is to include its general research costs in overhead expense [citing cases]."

${ }^{28}$ See ASPR 15-201.2. 
normal accounting system in order to reflect more accurately the true cost of his government contracts. ${ }^{29}$ Moreover, the underlying reason for having section fifteen of ASPR at all would appear to be that consistently applied accounting principles are not sufficient to protect the government's interest.

The Tracerlab opinion also lays considerable emphasis upon the argument that since IR\&D is itself an indirect or overhead expense, it should not be required to bear its share of other indirect expenses. This reasoning overlooks the fact that the terms "direct" and "indirect" are relative terms, depending upon the level at which they are used. While it is true that general research is an indirect expense in the sense that it is normally apportioned among the various production divisions, this is because the cost accountant is normally interested in the total cost of the various production divisions. If a general research division were created and the accountant were interested in determining the total cost of this general research division, it would be necessary that the division bear a proportionate part of the indirect costs of other staff divisions. ${ }^{30}$ Moreover, when a contractor undertakes an $R \& D$ contract on a cost-reimbursement basis for the government, this contract is required to bear its proportionate part of the overhead and administrative costs of contractor's operations.

Prior to I959, ASPR did not expressly deal with this problem; but in that year the ASPR was amended to provide that IR\&D would include its appropriate share of indirect and administrative costs "unless the contractor, in accordance with his accounting practices consistently applied, treats such costs otherwise." ${ }^{\text {11 }} \mathrm{Un}$ fortunately, this provision probably poses more questions than it answers. In the first place, the phrase "accounting practices consistently applied" is nowhere defined. Has the contractor complied therewith by applying a consistent practice throughout his entire organization for a single year or, as is more likely, must a history of this accounting practice be shown? A literal interpretation of the "unless" clause would also work an injustice upon those contractors who previously had accepted the government's practice of burdening IR\&D since they would now be bound thereby, while those contractors who had refused to do so would be protected by their contrary but consistently applied practice.

The preferable interpretation of the "unless" clause set forth above would appear to be that it is subject to the general limitations on allowability applicable to all contractor costs-reasonableness, allocability, and conformance with generally accepted accounting practices. ${ }^{32}$ In other words, the clause does not mean that an

\footnotetext{
${ }^{20}$ Olin Mathieson Chemical Corp., ASBCA No. 6468, I961-2 BCA \3126; Plasmadyne Corp., ASBCA No. 7731, 1962 BCA I 3452, at 17,684:

"While under the decision of this Board a contractor is usually held to the method of allocating overhead previously followed, when it is demonstrated that such method results in an unreasonable price and it is demonstrated that a different method produces a reasonable price, then the method originally utilized must be abandoned."

${ }^{30}$ See Cost Accountant's Handooox $133-34$ (T. Lang ed. 1947). See also Trueger, op. cit. supra note I0, at $266-67$.

${ }^{31}$ ASPR $15-205 \cdot 35(f)$.

${ }^{32}$ See ASPR I5-201.2.
} 
incorrect method is rendered acceptable by its consistent use, but rather that a contractor will not be required drastically to alter his accounting methods if he follows some other method which effectively segregates the IR\&D costs, both direct and indirect, from the government contract costs.

II

\section{IR\&D EXpenditures Since I960}

In late 1959 the cost principles of ASPR were extensively revised and the present principles relating to IR\&D were prescribed..$^{33}$ The revised principles were required to be incorporated into all cost-reimbursement type contracts executed after July $\mathrm{I}$, $1960 .^{34}$ An interesting case arose concerning a government contractor whose contracts incorporated the pre-rg60 ASPR, but who sought to take advantage of the liberalized IR\&D provisions after the change. ${ }^{35}$ The contractor argued that paragraph (c) of the Negotiated Overhead Rates clause ${ }^{36}$ did not incorporate the ASPR as in effect on a certain date, but rather applied any version of ASPR in effect at any pertinent time during the contract performance period. Specifically rejecting this contention, the ASBCA noted that ASPR is subject to unilateral change on the part of the government, and if the contractor's contentions were valid, the provision incorporating current ASPR cost principles would be an illusory stipulation establishing nothing of any fixed significance.

\section{A. Present ASPR Treatment of IR\&D}

The 1959 change first introduced the phrase "independent research and development" into the ASPR. It also defined for the first time "basic research," "applied research," and "development," although it was apparent from the beginning that there were no clear-cut dividing lines between the three. Basic or so-called "blue sky" research is defined as the increasing of knowledge in science generally, but not any practical application thereof. Applied research ordinarily follows basic research and attempts to advance the state of the arts, still without attempting to develop any specific articles or services to be offered for sale. ${ }^{37}$ Development is the systematic use of scientific knowledge directed toward the production or improvement of "useful products to meet specific performance requirements."38

The new principles undoubtedly were intended to liberalize as well as clarify, and independent research is broadly stated to be an allowable cost so long as it is allocated to all work of the contractor. ${ }^{39}$ This rather broad language of allowability is how-

${ }^{33}$ ASPR $15-205.35$ as promulgated in Change 50 to the 1955 ASPR, dated Nov. 2, 1959.

at See the instructions accompanying Change 50. A letter from the Assistant Secretary of Defense to the Secretaries of the Army, Navy, and Air Force, dated February 1o, 1960, provided that existing contracts would continue to be governed by the cost principles incorporated therein.

${ }^{35}$ General Analysis Corp., ASBCA No. 6920, I 962 BCA I 3337.

3s See note 12 supra.

${ }^{37}$ ASPR $\times 5-205 \cdot 35$ (a).

${ }^{38}$ ASPR I5-205.35(b).

${ }^{30}$ ASPR I5-205.35(d). 
ever qualified by three tests contained in ASPR $15-205.35(\mathrm{~h})$ : the expenditures must be reasonable; they must be part of a broad, well-managed, and planned program; and the expenditures should be scrutinized with great care in connection with contractors whose work is predominantly or substantially with the government.

Allowability of independent development is more restrictive than that of independent research. In addition to the restrictions of $15-205.35(\mathrm{~h})$, independent development must be related to the product lines for which the government has contracts and allocated as an indirect cost to all work of the contractor on all product lines related to the independent development. ${ }^{40} \mathrm{~A}$ more liberal test of allowability for independent development is prescribed where the contractor's normal course of business does not involve production work-a provision evidently intended to apply to those contractors whose end output is research. In such cases, independent development is allowable to the extent that it is related and allocated as an indirect cost "to the field of effort of government research and development contracts." ${ }^{41}$ This provision is rather ambiguous, but should also be read as requiring that the independent development costs be allocated to all work of the contractor which is related thereto.

In addition, under the current ASPR, numerous costs closely related to IR\&D are being reimbursed as "bidding costs." ASPR 15 -205.3 provides that the costs of preparing bids or proposals on potential government and nongovernment contracts, including the development of engineering and cost data, are allowable as indirect costs. Thus a contractor who receives a complicated request for proposals and is given five months for compiling his data and submitting his proposal would incur heavy expenditures in preparing such proposal; and much of the technical preparation would involve expenditures little different from the costs incurred in an IR\&D program. Such costs would be an allowable item of overhead in the year incurred (and therefore chargeable pro rata to any government contracts then in existence), whether or not the individual contractor was successful in securing the contract and whether or not his proposal was submitted in answer to a government solicitation. In effect, the contractor is encouraged to classify these costs as bidding costs rather than IR\&D since the latter are often subject to various costsharing arrangements.

\section{B. Capitalization of IR\&D Expenditures}

IR\&D expenditures normally are charged as a cost of doing business in the year incurred and are prorated as an item of overhead to the contractor's various product lines in that year. This usually would be to the contractor's benefit from both a federal income tax standpoint (since his net income and therefore his tax would be

${ }^{10}$ ASPR I5-205.35(e). Although the ASPR wording is not entirely clear, the intent appears to be that the independent development expenses be allocated to all related product lines, and not mercly to those related product lines for which the government has contracts.

${ }^{11}$ ASPR ${ }^{15-205.35(e) . ~(E m p h a s i s ~ a d d e d .) ~}$ 
lower) and from a government contract standpoint (since the reimbursement would be in the same year in which the expenditures were incurred).

There are a number of cases, however, which have allowed the contractor to capitalize such costs and to charge them off in subsequent years. In one of the earliest cases, for example, the contractor was allowed to charge pre-contract research and development costs against a subsequent cost-plus-fixed-fee production contract. ${ }^{42}$ In a more recent case, the contractor in performing certain fixed-price $R \& D$ contracts incurred costs substantially in excess of the contract price. These excess costs were charged to a general and administrative expense account entitled "Amortization of Patent Rights" and were written off over a five-year period. The ASBCA held that such costs were properly chargeable against subsequent CPFF government contracts as "research and development costs specifically applicable" to the contracts $^{43}$ under the pre-I960 ASPR I5-204(s). ${ }^{44}$ Of course, where the IR\&D costs have been charged to overhead which has been allocably charged to previous government contracts, the costs may not be reimbursed a second time under a subsequent production contract. ${ }^{45}$ There is also a line of price redetermination cases which have disallowed the amortization of $\mathrm{R} \& \mathrm{D}$ expenditures. ${ }^{46}$

The only express consideration of this problem in the current ASPR is a rather perplexing provision that research and development costs (whether or not capitalized) which were incurred in accounting periods prior to the award of a particular contract are unallowable except where allowable as precontract costs. ${ }^{47}$ Since IR\&D costs normally would not qualify under the narrow definition of precontract costs, ${ }^{48}$ the effect of this provision appears to be that where a contractor capitalizes his IR\&D expenses and then amortizes them over a period of years, new contracts must bear no portion of the IR\&D costs which were incurred prior to the award of the contract. If this provision were strictly applied, it would require that the overhead amortization be computed separately for each new contract, ${ }^{49}$ a procedure which apparently is not now being followed, probably because few contractors amortize their IR\&D costs. Moreover, the cited provision applies only to costs incurred prior to the award of a particular contract, and does not address itself to costs incurred subsequent to award but prior to the current fiscal year. The provision would be more workable if it excluded all IR\&D costs incurred prior to the contractor's current fiscal year.

${ }^{42}$ Bell Aircraft Corp. v. United States, roo F. Supp. 66r (Ct. Cl. I95x), affd per curiam, 344 U.S. 860 (1952). The holding is not as clear as it might be since much of the Court of Claims' opinion was directed to the issue of whether or not the government was bound by the contracting officer's decision to allow the costs.

${ }^{43}$ Kellett Aircraft Corp., ASBCA No. 5658, xg60-I BCA ף 2584 .

"See note 5 stipra.

${ }^{6}$ S.S. White Dental Mfg. Co., Inc., ASBCA 40r2, I960-r BCA ๆ 2588.

${ }^{16}$ Polytechnic Research \& Development Co., Inc., ASBCA No. 1995, Oct. 13, 1954; Gar Wood Industries, Inc., ASBCA Nos. 2327 and 2329, March 30, r956; and Audio Products Corp., ASBCA No. 2690, 1957-I BCA \& 1289 .

${ }^{17}$ ASPR $15-205.35(\mathrm{~g})$.

${ }^{18}$ See ASPR $15-205.30$.

${ }^{10}$ See Trueger, op. cit. supra note Io, at 133 . 
There are a number of instances in which precontract research and development costs should be allowable against subsequent government contracts even though the costs fail to qualify as "precontract costs" under ASPR 15-205.30. For example, if a commercial contractor develops through his own independent efforts a product which is subsequently sold to the government, and if these development costs have not been previously included in the overhead which was allocated in part to government contracts, the government should pay its allocable share of these development costs as one of the components of the price it pays for the product. If the product is sold under a cost-reimbursement type contract, an allocable share of the precontract developmental costs should be allowable as direct costs..$^{50}$ In any case, the preferable method of dealing with such costs would be as part of the precontract negotiations.

\section{Advance Agreements}

As has been indicated above, the present ASPR provisions relating to the allowability of IR\&D expenditures give rise to a number of unresolved problem areas, not the least of which is distinguishing independent research from independent development. Thus, the contractor who undertakes an IR\&D program cannot be sure whether any portion of that program will be reimbursable under his government contracts; and to a great extent he assumes the risk that the costs subsequently will be determined nonallowable. In order to alleviate this hardship, the ASPR provides a procedure whereby an advance understanding may be negotiated between the parties as to the allowability of IR\&D costs. ${ }^{51} \mathrm{~A}$ recent case indicates that, for a valid advance agreement, there must be both $(\mathrm{r})$ an advance understanding (prior to the costs being incurred) and (2) its incorporation into the contract. ${ }^{62}$ Although not all cases have imposed such rigorous formal requirements, ${ }^{53}$ counsel for both the government and the contractor are well advised to assure that any such agreement be explicit and in writing.

The IR\&D reimbursement section indicates that advance agreements are particularly important in those situations where the contractor's work is predominantly or substantially with the government. ${ }^{54}$ This has been administratively determined to apply to those contractors whose work is fifty per cent or more with the government, and in the past almost all advance agreements have been negotiated with such contractors. The same section of ASPR also indicates that in some cases it may be desirable for the government to bear less than an allocable portion of the cost of the

${ }^{80}$ See ASPR 15-202.

${ }^{81}$ ASPR I5-205.35(h) and 15-107(v).

52 National Research Corp., ASBCA No. 7524, I962 BCA 13526.

${ }^{83}$ There are a number of cases which have held the government bound by various types of advance understandings, sometimes even when not in writing. See, e.g., H. A. Ely Publications, Inc., ASBCA 49.5.2, I959-r BCA I 2102; General Dynamics/Astronautics, ASBCA 6899, I962 BCA \$3391; Spaco Manufacturing Co., Inc., ASBCA No. 6402, 1961-I BCA \3020. A far different result is reached where the contracting officer initially expressed disapproval of the proposed expenditure. General Dynamics/ Astronautics Corp., ASBCA. No. 7650, 1963 BCA I 3685 .

${ }^{84}$ ASPR I5-205.35(h). 
IR\&D program. In these cases, the advance agreement may limit the government's participation by agreement to support certain of the contractor's IR\&D projects but not all of them, by agreement that the government will allocably support the research to a maximum dollar limitation, or by agreement that the government will accept its allocable share of only a certain percentage of the contractor's IR\&D. This latter method of cost limitation, the frequently criticized cost-sharing agreement, has been used almost exclusively.

In summary, it may be said that the advance agreement procedure offers advantages to both parties: the contractor knows in advance whether the government will accept his IR\&D program, and the government may specify in advance those projects which it is willing to underwrite. Where the government's contribution is to be limited, however, either of the other two methods of limitation would appear to be preferable to the arbitrary cost-sharing formula.

\section{Negotiation of Independent Research and Development Expenditures Where More Than One Military Department Is Involved}

An individual government contractor may have contracts with more than one military department, and it would be inefficient and costly to require that he negotiate the overhead rate, or specific items such as IR\&D, separately with each department. For this reason, the Defense Department has provided an orderly procedure whereby an individual service is designated to negotiate the allowability of IR\&D for all three services. ${ }^{65}$ The military services are required to conduct such joint negotiations in all cases where IR\&D costs are substantial, where a substantial portion of the contractor's business is with the Defense Department, and where the contractor's defense work involves contracts with more than one military department. ${ }^{5 B}$

Since highly specialized and technical considerations must be weighed in evaluating a contractor's IR\&D program, the Defense Department has also established the Armed Services Research Specialists Committee which the sponsoring military department may call upon for assistance in IR\&D negotiations. The Committee is composed of four experts in the field of research and development, one from the Office of the Secretary of Defense and one each from the Army, Navy, and Air Force. Its activities are to review the contractor's IR\&D program to determine whether there has been an adequate segregation between independent research and independent development by the contractor, and to make recommendations to the sponsoring department "on the scientific and technical factors affecting the basis or extent to which such programs should be supported."57 Unfortunately, the Committee has not been widely utilized in the past; and even where used, it has done little more than review the brochures submitted by contractors to determine whether an adequate segregation has been made between independent research and independent development.

\footnotetext{
${ }^{55}$ Department of Defense Directive 4105.52, June 28, 1960.

${ }^{50}$ Id. qIV.A.

"Id. IIII.A.
} 
III

Proposed Government-Wide IR\&D Regulations

Under the authority of the same presidential letter which initiated the Bell Report ${ }^{58}$ the Bureau of the Budget has instituted a government-wide effort to achieve uniformity in the contract cost principles applied by the various executive agencies. To date, much of this effort has centered upon the differing cost principles applied toward a contractor's IR\&D program, the Budget Bureau seeking uniformity of treatment by the Defense Department, the Atomic Energy Commission (AEC), and the National Aeronautics and Space Administration (NASA). ${ }^{50}$

The Budget Bureau study has indicated that in the immediate past, NASA and AEC have been more restrictive in allowing reimbursement of IR\&D than has the Defense Department. NASA, for example, will not reimburse IR\&D expenditures under a research contract placed with a commercial organization in response to an unsolicited proposal. $^{80}$ The AEC cost principles, like the pre-rg60 ASPR, provide that independent research and development costs are unallowable unless specifically provided for elsewhere in the contract. In order to secure an express provision for reimbursement elsewhere in the contract, the contractor must show that the IR\&D costs provide a benefit to the particular AEC contract for which such provision is sought. The AEC cost principles also require that IR\&D costs shall include an amount for absorption of their appropriate share of related indirect and administrative costs. ${ }^{61}$

As a result of the Budget Bureau study, representatives of Defense, AEC, and NASA have developed proposed government-wide IR\&D cost regulations, which were mailed to industry for comment in November, rg63. Pertinent parts of these proposed regulations are reproduced in the Appendix at the end of this article, the numbering being keyed to existing paragraphs of ASPR. Initial industry comment indicates a good deal of opposition to the proposed regulations, industry spokesmen having interpreted various provisions as being more restrictive of allowability than the present ASPR. For these reasons, it will probably be a number of months before final regulations are agreed upon and promulgated by the various procuring agencies.

A number of significant changes would be made in the present ASPR by the proposed regulations. The separate definitions of "basic research," "applied research," and "development" would be dropped, and IR\&D broadly defined to encompass all unsponsored costs of scientific and technical work, other than manu-

${ }^{58}$ U.S. Bureau of the Budget, Report to the President on Government Contracting for Research and Development, S. Doc. No. 94, 87th Cong., 2d Sess. (1962).

50 The primogenitor of the present inquiry within the Defense Department was a letter from the Acting Director, Bureau of the Budget, to the Secretary of Defense, dated Jan. 22, 1962. Even before the Budget Bureau letter, however, revision of certain areas of IR\&D coverage had been suggested to the ASPR Committee.

${ }^{60}$ Letter from Director of Administration, NASA, to Deputy Director, Bureau of the Budget, Dec. 6, I96r.

${ }^{61}$ Letter from Deputy General Manager, AEC, to Deputy Director, Bureau of the Budget, Dec. I, Ig6r. See also AEC PR 9-I5.50I0-12. 
facturing and production engineering costs. ${ }^{62}$ As a corollary, scientific and engineering work leading to the submission of a bid or proposal or to the award of a contract is specifically defined as being within IR\&D. The "bidding costs" section of the proposed ASPR is restricted to administrative costs such as physically preparing and submitting technical proposals and cost data. ${ }^{03}$

While these definitional changes may facilitate administration of the IR\&D section, since virtually all independent scientific and technical effort will be treated thereunder, this approach also has disadvantages. Since all IR\&D will be classed in a single category, it will be difficult to encourage a particular type of IR\&D, such as basic research, for example. Moreover, IR\&D costs are usually subjected to a cost ceiling, and there are certain costs included within the proposed definition of IR\&D which probably should not be subjected to such a ceiling. Notable among these is the cost of technical and scientific work undertaken in direct response to a government solicitation; such costs should be properly includable in overhead whether or not a contract ultimately results from the work.

There is a definite improvement made in requiring that IR\&D be required to bear its proportionate part of overhead expenditures. ${ }^{64}$ By this requirement, the amounts stated as being IR\&D will be more meaningful, and the government will be enabled to evaluate the program in terms of its total cost.

Improvements are also made in the area of advance agreements. ${ }^{65}$ Such agreements are encouraged not only with respect to contractors whose work is "predominantly or substantially with the government," ${ }^{268}$ as is true under the present ASPR, but also in those cases where "reasonableness or allocability are difficult to determine." It is to be hoped that this new language will encourage greater use of the advance agreement, with corresponding greater predictability of the allowability of IR\&D prior to the costs being incurred. In addition, the use of arbitrary, percentage cost-sharing arrangements will no longer be sanctioned in IR\&D advance agreements. Once it is determined that the program itself is allowable, the government will agree to absorb its allocable portion of such program up to a maximum dollar limitation. Thus, the advance negotiations will dwell upon three factors: whether the program itself is allowable, what is a reasonable maximum dollar limitation, and what are the proper bases for allocation?

In determining whether a particular cost is or is not allowable, the proposed cost principles have abolished the differing standards for independent research and independent development; but there is still a great lack of predictability in the area of IR\&D reimbursement. An effort is made to test IR\&D against the same general

\footnotetext{
Os Manufacturing and production engineering costs will continue to be governed by the provisions of ASPR 15-205.2x.

${ }^{\circ 3}$ See Proposed ASPR 15-205.3, Appendix A, infra.

ot Proposed ASPR 15-205.35(c). See also text accompanying notes r9-32 supra.

${ }^{\circ S}$ Proposed ASPR 15-205.35(f).

${ }^{\circ 0}$ Under the present ASPR, this was informally interpreted by the Military Departments to mean those contractors having $50 \%$ or more of their business with the government.
} 
standards applied to other costs, and IR\&D is stated to be allowable if reasonable within the criteria of ASPR 15-201.3 and appropriately allocated under ASPR 15-201.4. In view of the unique nature of IR\&D, however, such general standards have little meaning; and additional standards imposed by the proposed IR\&D section itself add little to the definition's specificity. ${ }^{88}$

Proposed ASPR $15-205.35$ (d) does provide that reasonableness is to be determined by comparing the cost of contractor's IR\&D program with the cost of IR\&D programs undertaken throughout the industry, but industry spokesmen have criticized this provision as requiring a meaningless comparison. Moreover, the provision ignores the most significant comparison: a comparison of the contractor's IR\&D program with the R\&D desired by the government and the total government funds available for support of $R \& D$.

As regards the allocation of IR\&D, the proposed regulations provide that within the standards of ASPR 15-203, IR\&D costs may be distributed throughout the contractor's operations, or only to a particular division, department, plant, group of plants, or a product line. ${ }^{69}$ This provision overlooks the fact that a truly equitable allocation of costs sometimes requires piercing the corporate entity. For example, at present numerous large corporations have created wholly-owned subsidiaries which are engaged virtually too per cent in R\&D under government cost-reimbursement contracts. Since the parent corporation invariably shares in the technological advancements of the subsidiary, it would not be unreasonable to require the parent to bear a portion of the subsidiary's costs, particularly in the area of IR\&D-where the government has no proprietary interest in the results produced, although the government in effect supports the IR\&D almost 100 per cent. Under the present ASPR, this would be remedied by a cost-sharing agreement whereby only a certain percentage of IR\&D would be allowed as an item of overhead; but since these agreements are no longer to be authorized under the proposed ASPR, some other means must be found to allocate equitably the IR\&D costs of these wholly-owned subsidiaries.

Costs of substantial activity to exploit new business opportunities outside of the contractor's existing organization and product lines are stated to be unallowable. ${ }^{70}$ This provision evidently was intended to codify such cases as The Martin Co., wherein the training and educational costs of developing a nuclear division in contractor's existing aircraft operations was held not to be a reimbursable item of overhead. ${ }^{71}$ The section should not be interpreted to exclude the costs of research on projects related to the contractor's operations, but not presently in the form of a salable product.

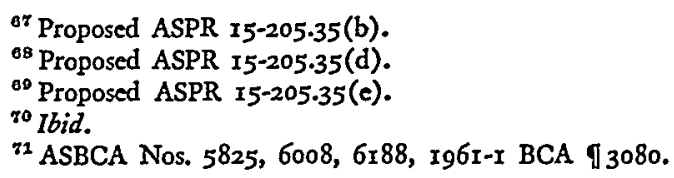




\section{Conclusions}

\section{A. Integration of IR\&D Into the Total Complex of Government Support} for Research and Development

The wisdom of government support for IR\&D through the overhead rate must be considered in the context of alternative means of government encouragement and support of $\mathrm{R} \& \mathrm{D}$. The income tax laws, for example, provide that subject to certain limitations, a taxpayer may elect to deduct research and experimental expenditures in the year incurred, to treat them as deferred expenses which may be amortized over a period of five years or more, or to capitalize them. ${ }^{72}$ In one respect these tax benefits are more meaningful than IR\&D reimbursement since the tax benefits are available to any commercial organization which engages in qualified $R \& D$, while IR\&D reimbursement is available only to those contractors having government costreimbursement type contracts. The new price negotiation policies of ASPR also provide that a contractor's profit may be higher if his record of past performance is favorable in the matter of contractor-initiated and financed research and developmental contribution. ${ }^{73}$ Presumably, such IR\&D would not justify increased profits in subsequent years if the cost thereof had been primarily assumed by the government in the overhead rate of previous cost-reimbursement type contracts.

Where direct government support of $R \& D$ is desired, several different means are available. Government laboratories and other installations may be operated with federal employees, or government-owned facilities may be operated by private contractors. Direct $R \& D$ contracts may also be placed with commercial or nonprofit organizations. $^{74}$ Finally, there is the legislation which authorizes basic research grants to nonprofit institutions of higher education or to nonprofit organizations whose primary purpose is the conduct of scientific research. ${ }^{75}$ A properly administered program of IR\&D reimbursement through the overhead rate must be evaluated in conjunction with these alternative means of government support for $R \& D$ and must be integrated therewith.

\section{B. Increasing and More Effective Use of Advance Agreements}

In the past, IR\&D reimbursement has been too often merely a question for the auditors, arising after the costs have been incurred and as a part of negotiating the postdetermined overhead rate. IR\&D reimbursement should be negotiated by procurement and technical personnel prior to the contract period through increasing use of the advance agreement. Such advance agreements should be utilized in all

${ }^{78}$ INT. REV. CODE OF I954, § I74.

${ }^{73}$ See ASPR 3-808.5(d)( 7 ).

${ }^{74}$ See Exec. Order No. I0521, §4, I9 Fed. Reg. 1499 (1954). See also Department of Defense Directive 3210.I, Oct. 26, 196I. For a discussion of the various legal problems arising in R\&D procurement, see Federal Bar Ass'n, Research and Development Procurement Law (Lazure \& Murphy ed. x957); Federal Publicattons Inc., Research and Development Contracting (rg63).

${ }_{75} 72$ Stat. 1793,42 U.S.C. § I89I (1958). See also Department of Defense Directive 32x0.2, Nov. 19, 1962; Whelan, Public Law 85-934: New Federal Support for Basic Scientific Research, 8 J. PUi. L. 462 (1959). 
circumstances where the contractor's IR\&D program is substantial and where he has sufficient cost-reimbursement type contracts to justify the cost. If it is thought that such widespread use of the advance agreement will impose an undue burden upon present government personnel, such agreements may be negotiated for a period of more than one year. The advance agreement should indicate those projects which the government is willing to reimburse pro rata through the overhead rate, as well as the maximum dollar amount of the government's contribution in a given year. Projects of primarily commercial application should be excluded. Once such an agreement has been executed, the auditor's role should merely be to assure that it has been implemented through acceptable accounting principles and procedures.

Government procedures must be streamlined to assure rapid negotiation of such advance agreements prior to the contract period. The traditional brochure describing the R\&D to be undertaken and the facilities to be utilized need not be as exhaustive as has been the case in the past. A summary of the IR\&D program, divided into specific projects, should be sufficient if supplemented by visits of government technical and procurement personnel to the contractor's plant. At the end of each year or other agreed period, the contractor should be required to furnish a summary evaluating the IR\&D undertaken and the results achieved. The administrative costs of preparing both the preliminary brochure (whether or not the government accepts the proposed IR\&D) and the year-end evaluated results should be allowable as overhead under any government cost-reimbursement contracts in effect in the year such costs are incurred.

Where it is desired to limit the government's contribution to a contractor's IR\&D program, this should be done by supporting some, but not all, of the proposed projects, or by imposing a realistic dollar ceiling on the total amount of IR\&D which will be reimbursed to a particular contractor as an item of overhead in a given year. As the proposed government-wide IR\&D principles have recognized, the use of arbitrary, percentage cost-sharing arrangements should be abolished. IR $\& D$, by the very nature of its inclusion within the overhead rate, is already subject to a cost-sharing formula depending upon the percentage of contractor's costs which are incurred under government cost-type contracts as compared to the costs incurred under other contracts.

\section{Meaningful Standards for the Allowance of IR $\& D$}

Advance agreements can never be the total answer in assuring predictability in the area of IR\&D reimbursement. This is so because there are numerous contractors whose IR\&D program is so small, or who have so few cost-reimbursement type government contracts, that the cost involved in negotiation of a detailed advance agreement is not justified. Meaningful criteria must be promulgated in the various procurement regulations so that such a contractor, when he undertakes a legitimate IR\&D program, will have some assurance that the program will be an allowable 
item of overhead. Of course, programs which are of primarily commercial application should be excluded.

Moreover, even as regards those contractors whose IR\&D programs will be subject to advance agreements, meaningful regulations need to be promulgated in order to guide the government personnel who will negotiate the adyance agreement. As to such contractors, considerably closer scrutiny will be required than for those contractors described in the previous paragraph. Perhaps a set of more detailed regulations should be promulgated exclusively for those contractors whose work is fifty per cent or more with the federal government.

In summary, it appears that there is a need for a searching inquiry into the area of IR\&D reimbursement for the purposes of integrating IR $\& D$ into the total program of government support for research and development, revising governmental practices and procedures in order to make more effective use of the advance agreement, and promulgating meaningful standards to govern the allowability of IR\&D expenditures. This need is not adequately being met by the Budget Bureau study or the proposed regulations recently mailed to industry for comment. If properly managed, integrated with the various direct means of support for R\&D, and subjected to meaningful standards of allowability, however, reimbursement of IR\&D through the overhead rate would appear to be a desirable method of government support for research and development, since the nation as a whole secures more than a dollar's worth of $\mathrm{R} \& \mathrm{D}$ for each government dollar expended.

\section{APPENDIX}

PROPOSED ASPR CHANGES RELATING TO INDEPENDENT RESEARCH AND DEVELOPMENT COSTS

(As Mailed to Industry in November 1963)

"Revise 15-205.3 to read:

"I5-205.3 Bidding Costs.

"(a) Bidding costs are limited to the administrative costs involved in preparing and submitting solicited and nonsolicited bids or proposals to customers (Government and non-Government) on proposed or potential contracts. Bidding costs include the cost of the physical preparation and publication of the technical proposal documents and also the cost of the preparation and publication of cost and such other administrative data as are necessary to support the contractor's bids or proposals.

"(b) Costs of independent research and development (including scientific and engineering work which is not sponsored by a contract, grant or other arrangement) as defined in $15-205.35$ (a) are not allowable as bidding costs.

"(c) Bidding costs for both successful and unsucessful bids normally will be treated as allowable indirect costs, provided the principles of I5-20I.4 and I5-203 are observed.

"Revise 15-205.35 to read:

"15-205.35 Independent Research and Development Costs. 
“(a) A contractor's independent research and development costs are the costs of scientific and technical work, under whatever name, (except manufacturing and production engineering costs, described in 15-205.21) which is not sponsored by a contract, grant, or other arrangement. Such work includes the scientific and engineering work leading to the submission of a bid or proposal or to the award of a contract (see 15-205.3).

"(b) A contractor's independent research and development costs are allowable as indirect costs (see 15-203) to the extent that they are (i) reasonable (see 15-201.3 and (d) below), and (ii) appropriately allocated (see 15-20r.4 and (e) below).

“(c) Research and development costs (including amounts capitalized), regardless of their nature, which are incurred in accounting periods prior to the award of a particular contract, are unallowable.

"(d) The reasonableness of a contractor's research and development costs will be determined on the basis of all pertinent considerations (see 15-20r.3) including the nature, results, and costs of previous activity, and the soundness of its management. Where appropriate, the reasonableness of a contractor's independent research and development costs will be determined on the basis of evaluations, industry-toindustry variations in such costs, and independent research and development cost norms characteristic of industries. Attention will be given to an appraisal of the quality of (i) a contractor's technical objectives which generate independent research and development, (ii) his technical and other planning activities to meet these objectives, (iii) his technical performance in relation to these plans, and (iv) his utilization of technical results, within his operations, all in comparison with those of other contractors.

"(e) A contractor's independent research and development costs will be distributed in accordance with the principles provided by $15-203$. This may point to a contractor-wide distribution or to distribution only to a particular division, department, plant, group of products, or a product line. The full direct and indirect costs (engineering and laboratory overhead, manufacturing overhead, and general and administrative expenses) of independent research and development projects shall be determined prior to allocation. The costs of substantial activity, conducted by a contractor to exploit new business opportunities and for which the contractor's existing organization and product lines do not permit reasonable or proper allocation, will be regarded as unallowable.

"(f) Advance agreements as described in 15-107 are particularly important with respect to contractors whose work is predominantly or substantially with the government or in those cases where reasonableness or allocability are difficult to determine. Where this procedure is used, the contractor's proposed independent research and development costs will be evaluated as to allowability (see (b) above) and, based on such evaluation, agreement will be reached on a maximum dollar limitation representing a reasonable independent research and development program and on the bases for its allocation." 